\title{
DOENÇAS SEXUALMENTE TRANSMISSÍVEIS
}

\section{Tumores Perianais Provocados pelo Herpes Simples}

\author{
Perianal Tumors Provoked by Herpes Simplex
}

\author{
SIDNEY ROBERTO NADAL - TSBCP ${ }^{1}$; LUIS ROBERTO MANZIONENADAL ${ }^{2}$ \\ ${ }^{1}$ Titular da Sociedade Brasileira de Coloproctologia; ${ }^{2}$ Acadêmico do $6{ }^{\circ}$ ano da Faculdade de Ciências Médicas da \\ Santa Casa de São Paulo - SP - Brasil.
}

NADAL LRM; NADAL SR. Tumores Perianais Provocados pelo Herpes Simples. Rev bras Coloproct, 2007;27(1): 093-095.

RESUMO: O Herpes simplex (HSV) é um DNA vírus que provoca afecções perianais, sendo considerada a causa mais comum das úlceras na região. Apesar da forma ulcerativa ser a mais conhecida, a literatura relata o aparecimento de lesões tumorais, nodulares ou hipertróficas relacionadas ao vírus. $O$ exame proctológico mostra tumores dolorosos, achatados, com superfície recoberta por ulceração rasa e com bordas bem delimitadas, elevadas e lobuladas, localizados na margem anal e/ou no sulco interglúteo, algumas vezes imitando condilomas virais ou carcinoma. A anamnese revela instalação insidiosa com crescimento lento e progressivo, além da história de tratamentos anteriores para úlceras herpéticas. O diagnóstico diferencial com carcinoma impõe a realização de biópsia para confirmação histológica. Esse exame revela hiperplasia epitelial moderada e denso processo inflamatório com linfócitos e plasmócitos. Células gigantes e multinucleadas são observadas na epiderme. Os testes imunohistoquímicos sugerem o HSV. A opção terapêutica inicial deve ser o tratamento medicamentoso. Importante definir o diagnóstico etiológico para aliviar o desconforto e evitar operação radical desnecessária, e introduzir medicação anti-retroviral nos portadores do HIV para melhora da imunidade.

Descritores: Tumor anal, Herpes simples hipertrófico, AIDS.

O Herpes simplex provoca afecções perianais, sendo considerada a causa mais comum das úlceras na região. ${ }^{1-3}$ É um DNA vírus que pode estabelecer infecções latentes por longos períodos sem ser percebido pelo sistema imune, desenvolvendo mecanismos alternativos para se evadir e reduzir o impacto dos processos de defesa específica do doente. É um alfa Herpesvírus com dois genótipos conhecidos, o tipo 1 (HSV-1) mais associado ao herpes labial e o tipo 2 (HSV-2) que determina lesões anogenitais. Entretanto, devido ao contato orogenital, o HSV-1 é responsável por 10 a $20 \%$ das lesões perianais $^{4-6}$ e sua incidência nesse local tem aumentado. ${ }^{6,7}$ Até dois terços da população sexualmente ativa têm herpes assintomático, e a maioria dissemina o vírus durante os períodos de latência. ${ }^{8}$ Mais preocupante é a prevalência do HSV-2 que quintuplicou em adolescentes e dobrou em adultos jovens durante as duas últimas décadas. ${ }^{9}$

Apesar da forma ulcerativa ser a mais conhecida, a literatura relata o aparecimento de lesões tumorais, nodulares ou hipertróficas relacionadas ao vírus. ${ }^{10-15}$ Esse aspecto vem sendo observado em doentes imunodeprimidos, entre eles transplantados em uso de medicação imunodepressora e portadores do vírus da imunodeficiência adquirida (HIV). ${ }^{13,15-17}$ Macroscopicamente, trata-se de tumores dolorosos, achatados, com superfície recoberta por ulceração rasa e com bordas bem delimitadas, elevadas e lobuladas, localizados na margem anal e/ou no sulco interglúteo, ${ }^{16,17}$ algumas vezes imitando condilomas virais ${ }^{15}$ ou carcinoma. ${ }^{13,16,17}$ Lesões semelhantes também foram descritas no lóbulo da orelha e ponta dos dedos, ${ }^{14}$ na língua, ${ }^{18}$ no pênis e na bolsa escrotal, ${ }^{12}$ endobronquial, ${ }^{11} \mathrm{e}$

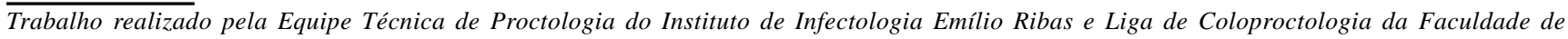
Ciências Médicas da Santa Casa de São Paulo - São Paulo - SP - Brasil. 
no colo do útero. ${ }^{8} \mathrm{O}$ quadro clínico mostra instalação insidiosa com crescimento lento e progressivo, ${ }^{12,13,15-18}$ além da história de tratamentos anteriores com aciclovir para úlceras de etiologia herpética. ${ }^{12,13,15-17}$ Muitos desses doentes recebiam drogas anti-retrovirais e as contagens séricas dos linfócitos T CD4+ variavam entre 13 e $500 / \mathrm{mm}^{3},{ }^{12,13,15-18}$ o que mostra não haver correlação com estádios extremos de imunodepressão.

O motivo dessa evolução anômala não está definido, mas provavelmente o mecanismo deve ser imunológico..$^{15-17,19}$ Entre as hipóteses, há referências sobre a deficiência das células dendríticas plasmocitóides em produzir interferon-alfa, o que ocorre em doentes com AIDS e predispõe à doenças oportunistas. ${ }^{19}$ No entanto, foi citado que as mesmas células dendríticas da pele produzem fator de necrose tumoral alfa (TNF-alfa) induzindo proliferação dos queratinócitos que provocam hiperqueratose e acantose. ${ }^{15}$ Além disso, outros autores referiram que essas lesões podem ocorrer na síndrome da hiper IgE, doença causada por alteração congênita que causa infecções recidivantes por estafilococos, eczema, anormalidades ósseas e elevação dos níveis de imunoglobulina $\mathrm{E}(\mathrm{IgE}) .{ }^{21}$ Nesses casos, há diminuição dos linfócitos T CD4+e da produção das citocinas relacionadas aos processo inflamatório, propiciando às infecções. ${ }^{21}$ Entretanto, o herpes tumoral foi descrito em parcela mínima dos portadores de doenças que provocam imunodepressão.

O diagnóstico diferencial com carcinoma impõe a realização de biópsia para confirmação histológica. Esse exame revela hiperplasia epitelial moderada e denso processo inflamatório que inclui a hipoderme. A inflamação é composta principalmente por linfócitos e plasmócitos. ${ }^{12,13,17,18}$ Células gigantes e multinucleadas foram observadas na epiderme. ${ }^{12,13,15}$ Os testes imunohistoquímicos mostraram células positivas para HSV-2 e localizadas principalmente nas camadas média e superior do epitélio, sendo raras na camada basal.111. ${ }^{12,13,15,18}$ Todavia, o HSV do tipo 1 foi isolado em um caso. ${ }^{17}$ Outros agentes virais podem causar lesões verrucosas. Além daquelas induzidas pelo Papilomavirus (HPV), as provocadas pelo vírus varicela-zoster (VZV), pelo citomegalovirus (CMV), pelo Ebstein-Barr (EBV) e o molusco contagioso causado pelo Poxvirus devem ser afastadas. ${ }^{12,15}$

A opção terapêutica inicial deve ser o tratamento medicamentoso. $\mathrm{O}$ aciclovir oral foi efetivo em alguns casos, ${ }^{15,17,20} \mathrm{e}$ ineficaz em outros, após uso contínuo durante quatro meses. ${ }^{12,17} \mathrm{O}$ valacidovir ${ }^{12,13}$ e o famciclovir, ${ }^{20}$ ambos de uso oral, erradicaram as lesões em até 30 dias. $\mathrm{O}$ interferon beta, usado durante cinco semanas, reduziu a área doente, mas, não aliviou os sintomas. ${ }^{17} \mathrm{~A}$ brivudina, agente virustático, eliminou a doença em poucos dias. ${ }^{18} \mathrm{O}$ ganciclovir endovenoso tratou um dos doentes. ${ }^{17}$ Há relatos sobre a eficácia do imiquimode tópico no tratamento de lesões genitais. ${ }^{20}$ A biópsia excisional, extirpando toda área comprometida, foi realizada em tumores pequenos e a ressecção cirúrgica com rotação de retalho em lesão muito grande em região sacral, antes do diagnóstico definitivo, com alívio da síndrome dolorosa. ${ }^{17}$ Algumas recidivas ocorreram entre três meses e um ano. ${ }^{17}$ Nesses casos, o aciclovir tópico combinado como produto por via oral foi eficaz. É importante definir o diagnóstico etiológico para aliviar o desconforto e evitar operação radical desnecessária, e introduzir medicação anti-retroviral nos portadores do HIV para melhora da imunidade.

ABSTRACT: Herpes simplex is a DNA virus which provokes perianal lesions, and it is the most frequent etiology of anal ulcer. Despite the ulcerative herpes being known worldwide, literature relates a tumoral, or nodular, or hypertrophic form related to this virus. Proctological examination showed nodules with a verrucous appearance and an ulcerated surface at the anal margin, sometimes mimicking viral condylomas or carcinomas. Anamnesis reveals insidious installation, slow growth and prior treatments for herpetic ulcers. The differential diagnoses with cancer allow us to perform biopsies for histological confirmation. This exam reveals mild epithelial hyperplasia and dense inflammatory process composed of lymphocytes and plasma cells. Multinucleated giant epithelial cells may be seen in the epidermis. Immunohistochemical tests show HSV presence. Medical therapy is indicated. It is very important to establish the correct diagnosis to relieve symptoms and to avoid an unnecessary surgical treatment. Highly active anti-retroviral therapy (HAART) must be introduced for HIV-infected patients to improve immunity.

Key words: Anal tumors, Hypertrophic herpes simplex, AIDS 


\section{REFERÊNCIAS}

1. Desai VK, Kosambiya JK, Thakor HG, Umrigar DD, Khandwala BR, Bhuyab KK. Prevalence of sexually transmitted infections and performance of STI syndromes against etiological diagnosis, in female sex workers of red light area in Surat, India. Sex Transm Infect. 2003;79:111-5.

2. Johnson LF, Coetzee DJ, Dorrington RE. Sentinel surveillance of sexually transmitted infections in South Africa: a review. Sex Transm Infect 2005;81:287-93.

3. Workowski AK, Levine WC, Wasserheit JN. U.S. Centers for diseases Control and Prevention guidelines for the treatment of sexually transmitted diseases: an opportunity to unify clinical and public practice. Ann Intern Med. 2002;137:255-62.

4. Pereira Jr AC. Herpes Simples Genital. In, Passos MRL, Doenças Sexualmente Transmissíveis. Ed Cultura Médica, Rio de Janeiro, $3^{\text {a }}$ ed., 1991 p.107-114.

5. Ashley RL, Wald A. Genital Herpes: Review of the epidemic and potential use of type-specific serology.Clin Microbiol Rev 1999;12:1-8.

6. Ribes JA, Steele AD, Seabolt JP, Baker DJ. Six-Year Study of the Incidence of Herpes in Genital and Nongenital Cultures in a Central Kentucky Medical Center Patient Population. J Clin Microbiol 2001;39:3321-3325.

7. Lowhagen GB, Tunback P, Bergstrom T. Proportion of herpes simplex virus (HSV) type 1 and type 2 among genital and extragenital HSV isolates. Acta Derm Venereol 2002;82:118-20.

8. Maitra N, Gupta M. Seroprevalence and correlates of herpes simplex virus type-2 infection in a general gynecology clinic. Arch Gynecol Obstet. 2007;275:19-23.

9. Fleming DT, McQuillan GM, Johnson RE, Nahmias AJ, Aral SO, Lee FK et al. Herpes simplex virus type 2 in the United States, 1976 to 1994. N. Engl. J. Med 1997; 337:1105-1111.

10. Samaratunga H, Weedon D, Musgrave N, McCallum N. Atypical presentation of herpes simplex (chronic hypertrophic herpes) in a patient with HIV infection. Pathology 2001;33:532-5.

11. Nadal SR, Calore EE, Manzione CR, Horta SHC, Ferreira AF, Almeida LV. Hypertrophic herpes simplex simulating anal neoplasia in AIDS patients Report of five cases Dis Colon Rectum, 2005;48:2289-93.
12. Abbo L, Vincek V, Dickinson G, Shrestha N, Doblecki S, Haslett PA. Selective defect in plasmacyoid dendritic cell function in a patient with AIDS-associated atypical genital herpes simplex vegetans treated with imiquimod. Clin Infect Dis. 2007;44:25-7.

13. Fangman WL, Rao CH, Myers SA. Hypertrophic herpes simplex virus in HIV patients. J Drugs Dermatol. 2003;2:198201.

14. Upadya A, Tilluckdharry L, Nagy CD, Ravichandran P, Manthous C. Endobronchial pseudo-tumour caused by herpes simplex. Eur Respir J. 2005;25:1117-20.

15. Carrasco DA, Trizna Z, Colome-Grimmer M, Tyring SK. Verrucous herpes of the scrotum in a human immunodeficiency virus-positive man: case report and review of the literature. $\mathrm{J}$ Eur Acad Dermatol Venereol. 2002;16:511-5.

16. Tong P, Mutasim DF. Herpes simplex virus infection masquerading as condyloma acuminata in a patient with HIV disease. Br J Dermatol. 1996;134:797-800.

17. Weaver G, Kostman JR. Inoculation herpes simplex virus infections in patients with AIDS: unusual appearance and location of lesions. Clin Infect Dis. 1996;22:141-2.

18. Husak R, Tebbe B, Goerdt S, Wolfer LU, Zeichardt H, StofflerMeilicke $\mathrm{M}$ et al. Pseudotumour of the tongue caused by herpes simples type 2 in an HIV-1 infected immunosuppressed patient. Br J Dermatol. 1998;139:118-21.

19. Gubinelli E, Cocuroccia B, Lazzarotto T, Girolomoni G. Nodular perianal herpes simplex with prominent plasma cell infiltration. Sex Transm Dis. 2003;30:157-9.

20. Hershko K, Hershko AY, Leibovici V, Meir K, Ingber A. Herpes simplex virus infection in a hyper-IgE patient: appearance of unusual mass lesions. Acta Derm Venereol. 2002;82:204-5.

\section{Endereço para correspondência:} SIDNEY ROBERTO NADAL

Rua Dr. Virgilio de Carvalho Pinto, 381 / apto. 23

São Paulo (SP) - Brasil

05415-030

Tel./Fax (+55 11) 3337-4282

E-mail: srnadal@terra.com.br 